\title{
Statistical Research of Intersection of Technology and Entrepreneurship to Modern Practices, Policies and Promises
}

\author{
Peter O. Emereje ${ }^{1 *}$, C. U.Okolie ${ }^{2}$ and Tunde B. Adeleke ${ }^{3}$ \\ ${ }^{1}$ Department of Mechanical Engineering Technology, Delta State Polytechnic \\ Ogwashi-Uku, Delta State, Nigeria \\ ${ }^{2}$ Department of Chemical Engineering Technology, Delta State Polytechnic \\ Ogwashi-Uku, Delta Stete, Nigeria \\ ${ }^{3}$ Department of Production Engineering, Uniersity Of Benin \\ Benin City, Nigeria \\ ${ }^{*}$ Corresponding author's email: emerejepeter [AT] gmail.com
}

\begin{abstract}
There are many factors affecting the relationship between entrepreneurship and technology which has not been examined and studied and this has been a daunting problem for researchers in this area. This paper seeks to identify a number of factors that deal with technology and entrepreneurship with a view to understanding the intercorrelation among the identified factors thereby making us to know the intersection between them. It will help provide an overview of the state of the art in terms of technology and offers fresh insights for entrepreneurship policy for technology.

This study employed Kendall's Coefficient of Concordance (KCC) to rank the 32 identified variables and subsequently apply Principal Component Analysis (PCA. KCC was used to rank 32 identified variables in descending order of importance. Furthermore, the PCA was used to analyze a set of questionnaire crafted with the 32 variables and administered to knowledgeable respondents in the area. The outputs gotten from the statistical software include descriptive statistic, correlation matrix, eigenvalues, eigenvector, varimax rotated factor loadings, explained variance and factor plot, among others and thereafter interpretation was given. Result obtained unveiled five principal factors which were labeled creatively. Results obtained by KCC suggested that judges ranking were consistent. Also, PCA was indicating parsimony in data reduction from 32 variables to just five. The most influential variable by its factor loading of 0.954 is innovation. The import of this is that innovation which has the highest factor loading is the nexus between technology and entrepreneurship and should therefore be embraced.
\end{abstract}

Keywords---- Entrepreneurship, Innovation, Invention, Statistics

\section{INTRODUCTION}

Advances in entrepreneurship breakthroughs have undoubtedly been made possible through the use of technology. Similarly, intersection of technology in entrepreneurship is a vehicle that facilitates prosperity in individuals, firms, regions and nations. This study therefore serves an important function beyond satisfying intellectual curiosity. A lot of factors or variables arise from the point of the intersection. It is important that these factors are known and studied. Several journals were consulted in the course of crafting the set of questionnaires where 32 variables were obtained and administered to knowledgeable respondents in this area of study. A lot of researchers have tried to know the relationship between technology and entrepreneurship. Such researches include [1]-[2]. Knowledge and application of technology is prevalent. Yet, a comprehensive statistical study and understanding of the interface of variables concerning it is still lacking. It is important to know the nexus between these key elements of national growth and development. The main objective of this paper is hence to shed light and establish the pivotal point of intersection between entrepreneurship and technology as for emerging policies, promises and practices. Entrepreneurship has been defined and explained by many authors. More recently, the research field of entrepreneurship has been defined as analysis of "how, by whom and with what consequences opportunities to produce future goods and services are discovered, evaluated and exploited" [6]. As regards "how", it depicts the technology to be used by the entrepreneur. Closer scrutiny of the relationship between entrepreneurship and economic development is therefore needed. In order to stimulate the development-entrepreneurship discourse it may be necessary to first attempt to formalize or reconcile the 
role of entrepreneurship in the "grand ideas" of development economics, and to consider how this resonates with available evidence, and what this means for policy.

[5], famously defined the entrepreneur as the coordinator of production and agent of change ('creative destruction'). As such the "Schumpeterian" entrepreneur is above else an innovator. Scholars who share this view of entrepreneurship do not consider entrepreneurship to be very important in earlier stages of economic development - they see the contribution of entrepreneurship to be much more important at later stages of development, where economic growth is driven by knowledge and competition. At earlier stages of development, entrepreneurship may play a less pronounced role because growth is largely driven by factor accumulation [4].

Opportunity-motivated entrepreneurship may contribute to a nation's happiness, but only up to a point. Not everybody should become entrepreneurs, and the happiness of a nation cannot be -indefinitely increased by increasing the numbers of entrepreneurs [3].

[7]. Consider the literature on the impact of entrepreneurship on employment, innovation and productivity growth. They find that entrepreneurs do not spend more on R\&D than their counterparts, although the quality and efficiency of their innovation is higher, and that their contribution to productivity growth is low. The majority of entrepreneurs would earn higher incomes as wage employees, and while entrepreneurs create more jobs relative to non-entrepreneurs, the quality of jobs they create is lower. Hence not all entrepreneurs drive development, and not all entrepreneurs are innovative [6].

Principal component analysis (PCA) is a mathematical procedure that transforms a number of (possibly) correlated variables into a (smaller) number of uncorrelated variables called principal components. The first principal component accounts for as much of the variability in the data as possible, and each succeeding component accounts for as much of the remaining variability as possible.PCA reduces attribute space from a larger number of variables to a smaller number of factors and as such is a "nondependent". PCA is a dimensionality reduction or data compression method. The goal is dimension reduction. The aim of this paper is to identify a number of factors that deal with technology and entrepreneurship with a view to understanding the intercorrelation among the identified factors thereby making us to know the intersection between them.

\section{METHODOLOGY}

\section{Kendall's Coefficient of Concordance (KCC)}

32 identified scale items were identified from the literature reviewed in this area. This was then used to craft questionnaires that were administered to knowledgeable respondents in the area of entrepreneurship and technology. The scale items were administered to thirteen selected judges who ranked the first set of questionnaire in descending order of importance. The result of the respondents was used to generate a data matrix having a dimension of 13 by 32 . The measure of agreement among the judges who ranked the scale items was computed. The consistency in ranking is represented by Kendall's coefficient of concordance. Chi square $(\chi 2)$ was used to appraise the judges consistency in ranking the scale items. The Chi-square test, laid on a null hypothesis $\left(\mathrm{H}_{0}\right)$ proposes that the ranking by the 13 judges are discordant while the alternate hypothesis $\left(\mathrm{H}_{1}\right)$ proposes that the 13 judges were consistent. The null hypothesis was rejected at $\mathrm{p}$-value of 0.05 .

Kendall coefficient of concordance W,

$$
W=\frac{S}{\frac{1}{12} K^{2}\left(N^{3}-N\right)}
$$

Where,

$$
\begin{aligned}
& S=\sum\left(R_{j}-\frac{\sum R_{j}}{N}\right)^{2} \\
& \mathrm{R}_{\mathrm{j}}=\text { Column sum of ranks } \\
& \mathrm{N}=\text { Total number of Variables } \\
& \mathrm{S}=\text { Variance } \\
& \mathrm{K}=\text { Number of Judges }
\end{aligned}
$$

\section{Principal Component Analysis}

The second set of questionnaires that also contains 32critical variables was administered to other set of (100) respondents (Judges) for their expert evaluations. Respondent's scores were collated as data matrix and fed into StatisticXL software that provided the following output namely: descriptive Statistic, correlation matrix, eigenvalues, eigenvector, unrotated factor 
loading, case-wise factor scores, varimax rotated factor loadings, explained variance and factor plot, among others. On the basis of this statistiXL output, factor matrix interpretation was given and results discussed.

From the data matrix the correlation matrix was obtained using Equation (2) as stated below;

$$
r_{i j}=\frac{\sum x y}{\sqrt{\left(\sum x^{2}\right)\left(\sum y^{2}\right)}}
$$

where, $x=X_{i j}-\bar{X}_{. j}$

$$
y=Y_{i j}-\bar{Y}_{. j}
$$

$\bar{X}_{. j}=\frac{\sum_{i=1}^{N} X_{i j}}{N}$

$\bar{Y}_{. j}=\frac{\sum_{i=1}^{N} Y_{i j}}{N}$

$N=n_{j}=I=i_{\text {max }}$

$J=j_{\max }$

\section{RESULT AND DISCUSSION}

Result of Kendall Coefficient of concordance (KCC)

\begin{tabular}{|c|c|c|c|c|c|}
\hline $\mathbf{S} / \mathbf{N}$ & $\begin{array}{c}\text { Ranking } \\
\mathbf{R j}\end{array}$ & Variables description & $\mathbf{S} / \mathbf{N}$ & $\begin{array}{c}\text { Ranking } \\
\mathbf{R j}\end{array}$ & Variables description \\
\hline 1 & 13 & Innovation & 17 & 231 & Brainstorming \\
\hline 2 & 36 & Invention & 18 & 251 & Creation of New Market \\
\hline 3 & 96 & Technical Skills & 19 & 255 & Entrepreneurship as heffalump \\
\hline 4 & 108 & Research and Development & 20 & 260 & Policy formulation \\
\hline 5 & 113 & Technology Village & 21 & 264 & Intellectual property \\
\hline 6 & 147 & Curriculum review & 22 & 267 & Use of Patent \\
\hline 7 & 153 & Opportunity Recognition & 23 & 276 & Apoliticism \\
\hline 8 & 155 & Information Technology & 24 & 291 & Knowledge diffusion \\
\hline 9 & 155 & Risk taking & 25 & & Level of economic \\
& 166 & Incentivelopment \\
\hline 10 & 167 & Need for Achievement & 27 & 306 & Push and Pull Factors \\
\hline 11 & 175 & Uncertainty & 28 & 316 & Taxes and Entry \\
\hline 12 & 182 & Knowledge filter & 29 & 324 & Theoretical framework \\
\hline 13 & 198 & Serendipity & 30 & 344 & High transaction cost \\
\hline 14 & 209 & Entrepreneurship spirit & 31 & 344 & Importationitis \\
\hline 15 & 227 & Management of Technology & 32 & 686 & Entrepreneurship Workshop \\
\hline 16 & \multicolumn{2}{|r|}{}
\end{tabular}

Table 1 
Our results show that since $x_{c a l}^{2}=306.376>x_{t a b}^{2}=82.1914$, our experimental data do not provide sufficient proof for us to accept a null hypothesis of discordance among the judges who did the ranking. Thus the null hypothesis, Ho was rejected at a p-value of 0.05 , implying therefore that the judges ranking were in concordance, $\mathrm{W}=0.898570$ (which is meritorious).

\section{Result of Principal Component Analysis (PCA)}

The thirty two variables were developed into questionnaire and presented to 109 respondents where only 100 responses were retrieved.The data obtained from the questionnaire were arranged in matrix form based on the 5-point Resis-Likert scale.

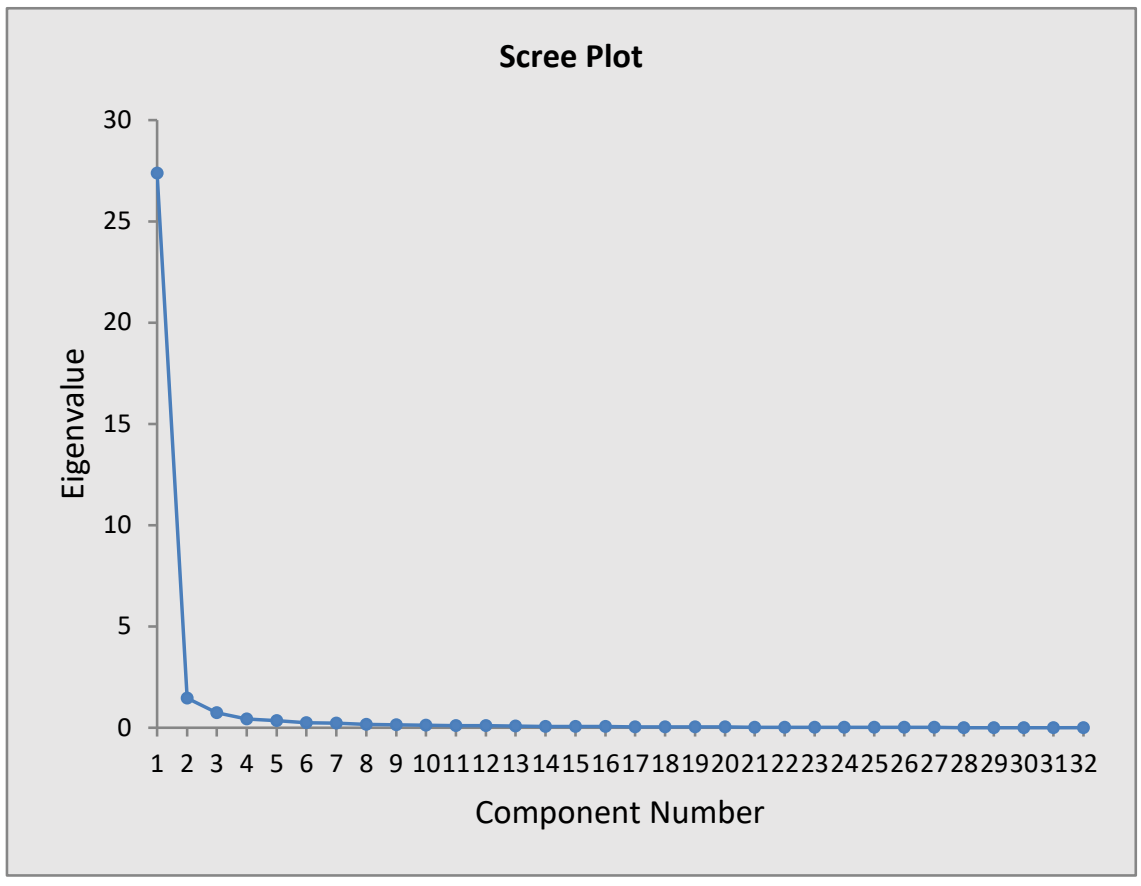

Fig. 1 Scree Plot 


\begin{tabular}{|c|c|c|c|c|c|c|}
\hline \multicolumn{7}{|c|}{$\begin{array}{c}\text { Varimax Rotated Factor Loadings matrix of } 32 \text { variables of Intersection between } \\
\text { Entrepreneurship and Technology }\end{array}$} \\
\hline $\mathrm{S} / \mathrm{N}$ & Variable & Factor 1 & $\begin{array}{c}\text { Factor } \\
2\end{array}$ & $\begin{array}{c}\text { Factor } \\
3\end{array}$ & $\begin{array}{c}\text { Factor } \\
4\end{array}$ & Factor 5 \\
\hline 1. & Innovation & 0.516 & 0.385 & 0.316 & 0.954 & 0.097 \\
\hline 2. & Invention & 0.815 & 0.463 & 0.228 & 0.057 & 0.103 \\
\hline 3. & Technical Skills & 0.452 & 0.776 & 0.255 & 0.236 & 0.134 \\
\hline 4. & Research and Development & 0.554 & 0.437 & 0.380 & 0.266 & 0.333 \\
\hline 5. & Technology Village & 0.530 & 0.742 & 0.207 & 0.137 & 0.126 \\
\hline 6. & Curriculum review & 0.540 & 0.824 & 0.300 & 0.142 & 0.067 \\
\hline 7. & Opportunity Recognition & 0.811 & 0.465 & 0.208 & 0.150 & 0.144 \\
\hline 8. & Information Technology & 0.543 & 0.737 & 0.222 & 0.185 & 0.081 \\
\hline 9. & Risk taking & 0.739 & 0.376 & 0.245 & 0.359 & 0.033 \\
\hline 10. & Incentives & 0.527 & 0.555 & 0.458 & 0.193 & 0.181 \\
\hline 11. & Need for Achievement & 0.730 & 0.425 & 0.211 & 0.165 & 0.144 \\
\hline 12. & Uncertainty & 0.723 & 0.344 & 0.355 & 0.268 & 0.113 \\
\hline 13. & Knowledge filter & 0.405 & 0.597 & 0.619 & 0.223 & 0.114 \\
\hline 14. & Serendipity & 0.382 & 0.795 & 0.312 & 0.246 & 0.146 \\
\hline 15. & Entrepreneurship spirit & 0.411 & 0.826 & 0.260 & 0.107 & 0.121 \\
\hline 16. & Management of Technology & 0.819 & 0.433 & 0.215 & 0.192 & 0.109 \\
\hline 17. & Brainstorming & 0.624 & 0.500 & 0.361 & 0.093 & 0.426 \\
\hline 18. & Creation of New Market & 0.426 & 0.667 & 0.238 & 0.115 & 0.149 \\
\hline 19. & Entrepreneurship as heffalump & 0.787 & 0.480 & 0.270 & 0.105 & 0.134 \\
\hline 20. & Policy formulation & 0.790 & 0.498 & 0.233 & 0.101 & 0.078 \\
\hline 21. & Intellectual property & 0.771 & 0.384 & 0.264 & 0.263 & 0.244 \\
\hline 22. & Use of Patent & 0.506 & 0.776 & 0.212 & 0.157 & 0.089 \\
\hline 23. & Apoliticism & 0.461 & 0.584 & 0.561 & 0.233 & 0.123 \\
\hline 24. & Knowledge diffusion & 0.592 & 0.469 & 0.383 & 0.176 & 0.468 \\
\hline 25. & Level of economic development & 0.470 & 0.786 & 0.234 & 0.124 & 0.106 \\
\hline 26. & Interdependence of technology & 0.7 & 0.380 & 0.267 & 0.254 & 0.031 \\
\hline 27. & Push and Pull Factors & 0.312 & 0.599 & 0.694 & 0.176 & 0.105 \\
\hline 28. & Taxes and Entry & 0.395 & 0.721 & 0.334 & 0.165 & 0.174 \\
\hline 29. & Theoretical framework & 0.667 & 0.344 & 0.374 & 0.320 & 0.126 \\
\hline 30. & High transaction cost & 0.398 & 0.710 & 0.419 & 0.204 & 0.154 \\
\hline 31. & Importationitis & 0.418 & 0.789 & 0.297 & 0.232 & 0.133 \\
\hline 32. & Entrepreneurship Workshop & 0.725 & 0.557 & 0.182 & 0.165 & 0.022 \\
\hline
\end{tabular}

Table 2 
Factor Interpretation;

FACTOR 1:DOGMATIC PRINCIPLES.

\begin{tabular}{|c|c|c|}
\hline \multicolumn{3}{|c|}{ Clusters 1(Factor 1): Dogmatic Principles. } \\
\hline S/N & Variable description & Factor loading \\
\hline 2 & Invention & $\mathbf{0 . 8 1 5}$ \\
\hline 4 & Research and Development & $\mathbf{0 . 5 9 4}$ \\
\hline 7 & Opportunity Recognition & $\mathbf{0 . 8 1 1}$ \\
\hline 9 & Risk taking & $\mathbf{0 . 7 3 9}$ \\
\hline 10 & Incentives & $\mathbf{0 . 5 2 7}$ \\
\hline 11 & Need for Achievement & $\mathbf{0 . 8 3 0}$ \\
\hline 12 & Uncertainty & $\mathbf{0 . 7 2 3}$ \\
\hline 16 & Management of Technology & $\mathbf{0 . 8 1 9}$ \\
\hline 17 & Brainstorming & $\mathbf{0 . 6 2 4}$ \\
\hline 19 & Entrepreneurship as heffalump & $\mathbf{0 . 7 8 7}$ \\
\hline 20 & Policy formulation & $\mathbf{0 . 7 9 0}$ \\
\hline 21 & Intellectual property & $\mathbf{0 . 7 7 1}$ \\
\hline 24 & Knowledge diffusion & $\mathbf{0 . 5 9 2}$ \\
\hline 26 & Interdependence of technology & $\mathbf{0 . 7 8 3}$ \\
\hline 29 & Theoretical framework & $\mathbf{0 . 6 6 7}$ \\
\hline 32 & Entrepreneurship Workshop & $\mathbf{0 . 7 2 5}$ \\
\hline
\end{tabular}

The PCA adopted with the aid of StatistiXL software, generated five (5) clusters or platoons. A principal factor embodying sixteen (16) variables which we creatively labelled;dogmatic principles. Seven (7) variables emerged top in the list on the basis of their high factor loadings; First on the list is Need for Achievement (N-Ach) wielding a factor loading of $\mathbf{0 . 8 3 0}$, under this it can be said any individual without $\mathrm{N}$-ach cannot be involved in technology entrepreneurship.

\section{FACTOR 2: CONCEPTUAL FRAMEWORK.}

\begin{tabular}{|c|c|c|}
\hline \multicolumn{3}{|c|}{ Clusters 2(Factor 2): Conceptual Framework. } \\
\hline S/N & Variable description & Factor loading \\
\hline 3 & Technical Skills & $\mathbf{0 . 7 7 6}$ \\
\hline 5 & Technology Village & $\mathbf{0 . 7 4 2}$ \\
\hline 6 & Curriculum review & $\mathbf{0 . 7 2 4}$ \\
\hline 10 & Incentives & $\mathbf{0 . 5 5 5}$ \\
\hline 13 & Knowledge filter & $\mathbf{0 . 5 9 7}$ \\
\hline 14 & Serendipity & $\mathbf{0 . 7 9 3}$ \\
\hline 15 & Entrepreneurship spirit & $\mathbf{0 . 8 2 6}$ \\
\hline 17 & Brainstorming & $\mathbf{0 . 5 0 0}$ \\
\hline 18 & Creation of New Market & $\mathbf{0 . 6 0 7}$ \\
\hline 22 & Use of Patent & $\mathbf{0 . 7 7 6}$ \\
\hline 23 & Apoliticism & $\mathbf{0 . 5 8 4}$ \\
\hline 24 & Knowledge diffusion & $\mathbf{0 . 4 6 9}$ \\
\hline 25 & Level of economic development & $\mathbf{0 . 7 8 6}$ \\
\hline 27 & Push and Pull Factors & $\mathbf{0 . 5 9 9}$ \\
\hline 28 & Taxes and Entry & $\mathbf{0 . 7 2 1}$ \\
\hline 30 & High transaction cost & $\mathbf{0 7 1 0}$ \\
\hline 31 & Importationitis & $\mathbf{0 . 7 8 9}$ \\
\hline 32 & Entrepreneurship Workshop & $\mathbf{0 . 5 6 7}$ \\
\hline
\end{tabular}

Table 4 
Management of Technology with factor loading 0.819 is very instructive. Management of Technology can be said to be a form of engineering economy as it depicts the real meaning as an interdisciplinary field integrating science, engineering and management knowledge and practice.MOT principles are not different from engineering economy as both have a central philosophy that focuses on creative thinking in design, research and development, engineering processes and so on in order to achieve improved output at minimum cost and reduced input.Invention with $\mathbf{0 . 8 1 5}$ factor loading is an event that produces a new idea, product, services, etc. Next is opportunity recognition with a factor loading of $\mathbf{0 . 8 1 1}$ which implies an individual being able to identify an opportunity and turn it into business.

Cluster 2 is creatively labeled Conceptual Framework. The factor loadings are all positive. The variables there in are majorly serendipity, use of patent, curriculum review and entrepreneurship spirit. It means that these factors are to be considered to strike a balance between technology and entrepreneurship

\section{FACTOR 3: ATTITUDINAL RATIO}

\begin{tabular}{|c|c|c|}
\hline \multicolumn{3}{|c|}{ Clusters 3(Factor 3): ATTITUDINAL RATIO } \\
\hline S/N & Variable description & Factor loading \\
\hline 13 & Knowledge filter & $\mathbf{0 . 6 5 9}$ \\
\hline 23 & Apoliticism & $\mathbf{0 . 5 6 1}$ \\
\hline 27 & Push and Pull Factors & $\mathbf{0 . 6 9 4}$ \\
\hline
\end{tabular}

Table 5

The third factors are a tripod involving knowledge filter apoliticism push and pull factors. Their factor loadings are middling which is suggesting that their role in entrepreneurship and technology is influential.

\section{FACTOR 4: INNOVATION}

\begin{tabular}{|c|c|c|}
\hline \multicolumn{4}{|c|}{ Clusters 4(Factor 4): Innovation. } \\
\hline S/N & Variable description & Factor loading \\
\hline 1 & Innovation & $\mathbf{0 . 9 5 4}$ \\
\hline
\end{tabular}

There is also a lone factor creatively labeled innovation. Innovation is works that delivers new goodness to new customers in new markets, and does it in a way that radically improves the probability equation. Its factor loading is very substantial.Innovation is a major driver of the economy.

\section{FACTOR5: SELF APPRAISAL}

\begin{tabular}{|c|c|rr|}
\hline \multicolumn{3}{|c|}{ Clusters 5(Factor 5): Self-Appraisal. } \\
\hline S/N & Variable description & Factor loading \\
\hline 17 & Brainstorming & $\mathbf{0 . 4 2 6}$ \\
\hline 24 & Knowledge diffusion & $\mathbf{0 . 4 6 8}$ \\
\hline
\end{tabular}

Table 7

Now, we encounter a dual factor creatively labeled self-appraisal. It involves brainstorming and knowledge diffusion. An intending entrepreneur should brainstorm very well so as to come out with a product that has value and there should be diffusion of knowledge from successful entrepreneurs so as to improve on the technical knowhow of businesses.

\section{CONCLUSION}

Taken together, it can be concluded that the major factor that can be said to be the intersection between technology and entrepreneurship is Innovation which has the highest factor loading of 0.954 . Accordingly, R\&D is an integral part of innovation is a major driver of the economy. With grim determination and resoluteness, innovation charts a course. Essential 
ingredients of innovation include Ideation, idea execution, addressing a real challenge, adding value both for the innovator and end-user. It is so because innovation is always forward looking which is the hallmark of the intersection between technology and entrepreneurship.

\section{REFERENCES}

[1] T. Bailletti, "Technology Entrepreneurship": Overview, Definition and distinctive aspects, technology innovation management review,: pp 5- 12, February 2012.

[2] B. Bamiro, "Engineering Capacity Building towards National Development" $21^{\text {st }}$ Engineering Assembly by Council for the Regulation of Engineering in Nigeria (COREN), Abuja Nigeria, 2012.

[3] Y.Carlisle, and E. Macmillan, "Innovation in organizations from a complex adaptive systems perspective" Emergence, complexity and organizations 8, no 1, 2-9, 2006.

[4] W. Naude and T. Gries, "Entrepreneurship and human

development" A capability approach; Journal of Public Economics, Volume 3 issue 1, pp 216 - 224, 2011

[5] S.Nicholas, and N. Armstrong, "Engineering entrepreneurship: Does entrepreneurship have a role in engineering education, IEE Antennas and Propagation Magazine, Vol. 45, No 1, February 2003.

[6] S. Shane, and S. Venkataraman, 'The Promise of

Entrepreneurship as a Field of Research’, Academy of Management Review, 25(1): pp21-26, 2000.

[7] M. VanPraag, and P. Versloot, "What is the Value of Entrepreneurship" A Review of Recent Research, Small Business Economics, vol.29: pp351-382, 2007. 